\title{
Die bydrae en relevansie van die missiologiese besinning in die GKSA
}

\author{
J.A. van Rooy \\ Departemente Missiologie \\ Potchefstroomse Universiteit vir $\mathrm{CHO}$ \\ POTCHEFSTROOM
}

\begin{abstract}
The contribution and relevance of missiological reflection in the Reformed Churches in South Africa

Taking into account the small number of missiologists in the Reformed Churches in South Africa, the contribution of this small denomination towards the development of the theology of mission is remarkable. Apart from many publications of a popular nature, almost a hundred scientific dissertations, books or articles have appeared during the last thirty years, covering the fields of inter alia, the biblical foundations of mission and the theology of mission. These fields can be divided into five sub-themes, to wit: the history of missiology, reflection on the nature of mission and evangelism, the dogmatic basis of mission, the nature of salvation and ecclesiological aspects of mission. Additional fields covered include reflection on the practice of mission (which includes mission strategy and means and methods of mission), the socio-economical and cultural dimensions of mission, the theory of communication, syncretism, different religions and history of mission.
\end{abstract}

\section{Inleiding}

In verhouding tot die grootte van die klein kerkefamilie het die Gereformeerde Kerke in Suid-Afrika 'n missiologiese oevre van verrassende omvang en verskeidenheid voortgebring - byna 'n honderd artikels en ander publikasies. Dit openbaar 'n wye veld van belangstelling en kundigheid en dek alle denkbare onderafdelings van die Missiologie. Agtereenvolgens word in hierdie artikel die bydraes bespreek volgens die verskillende onderwerpe wat daarin aangesny word. Verskeie publikasies dek meer as een afdeling. In daardie gevalle word die betrokke publikasie bespreek 
onder die onderwerp waartoe dit die mees betekenisvolle bydrae lewer. Aangesien die Skrif geen aanleiding gee tot prinsipiële onderskeiding tussen sending en evangelisasie nie, word albei onderwerpe onder dieselfde hoofde bespreek.

\section{Die Bybelse fundering van die sending}

Prof. Hugo du Plessis (1963a) het reeds dertig jaar gelede een van die mees uitstaande bydraes tot die Bybelse fundering van die sending gelewer in sy publikasie ' $n$ Banier van die volke. Tot op daardie datum was dit seker die grondigste en mees oorspronklike uiteensetting van die sendinggedagte in die Ou Testament wat in Suid-Afrika verskyn het, en het dit nuwe insigte na vore gebring waaruit ook missioloë in die buiteland veel kon leer. Hierdie publikasie het vanweë die breedheid en diepte van insig Du Plessis se reputasie as ' $n$ vooraanstaande missioloog van sy tyd in Suid-Afrika gevestig. Du Plessis sien af van die vroeëre benadering om die sendinggedagte van die Ou Testament in enkele tekste of uitsprake te soek, en dui aan hoedat die hele openbaring oor God en sy verhouding tot Israel en die volkere eintlik 'n ontsaglik breë basis vir die sendinggedagte daarstel.

Floor (s.j.) skryf oor "Die Eksodus-motief in die Swart Teologie". Wat die Nuwe Testament betref, is die mees uitstaande bydrae seker die proefskrif van P.J. Buys (1989), eerder (1986c) voorlopig uitgewerk in 'n artikel, oor die verhouding tussen gemeentebou en evangelisering. In sy proefskrif toon Buys eksegeties aan hoedat die geestelike en numerieke groei van die Nuwe-Testamentiese kerk saamhang en nie van mekaar geskei kan word nie. Hy toon onder andere aan dat die terme vir 'opbou' dwarsdeur die Nuwe Testament ook uitbreiding impliseer; dat terme wat evangelisering aandui, op sowel versterking in die geloof as evangelisering na buite kan dui; en dat terme wat lering aandui, almal 'n missionêre dimensie veronderstel. Oor die missionêre karakter van die Christelike gemeente is verder ook van belang "Kerk en sending" (Van Rooy, 1966), "Die missionêre gemeente" van Floor (1988) en "In hoever behoort sending tot die wese van die kerk?" van M.A. Kruger (1970). P.J. Buys (1986a) het geskryf oor "Bybelse gesigspunte oor die evangeliseringstaak van die kerk".

'n Belangrike bydrae oor die struktuur van die sendingwerk volgens die Nuwe Testament is dié van Floor (1964), "In dieselfde spore", waarin hy grondliggende riglyne gee vir die studie van die aard van die diens van sendeling en evangelis, die inhoud van die sendingprediking en die aard van gemeente-opbou. Oor die inhoud van 'stigtelike' prediking het ook Sny- 
man (1972) 'n deeglike eksegetiese en praktiese studie gelewer oor die inhoud en noodsaak van 'stigtelike' prediking in opvolging van 'stigtingsprediking'.

Getrou aan hulle begaandheid oor 'n Bybelse uitgangspunt, het missioloë uit die Gereformeerde Kerke dus uit die Skrif grondige aanvoorwerk vir die missiologie gedoen.

\section{Teologiese fundering van die sending}

\subsection{Geskiedenis van die Sendingwetenskap}

Oor hierdie onderwerp het H. du Plessis (1960a) ook 'n besondere betekenisvolle bydrae gemaak met sy publikasie Geskiedenis van die Sendingwetenskap, waarin sy wye belesenheid, teologiese insig en kritiese vermoëns duidelik is. Tot op daardie tydstip was dit die eerste omvangryke bydrae oor die onderwerp in Afrikaans. Later skryf hy ook 'n diepsinnige artikel oor die onderwerp "Die sendingroeping in verhouding tot die werk van God" (Du Plessis, s.j.).

\subsection{Wat is sending/evangelisering ?}

M.A. Kruger het 'n belangrike bydrae gemaak in sy twee artikels (1985, 1988) oor 'n onderwerp wat reeds vantevore deur J. van V. du Plessis (1982) aangesny is. In hierdie artikels toon hy op grond van 'n grondige eksegetiese ondersoek aan dat die Skrif geen basiese onderskeid maak tussen wat tradisioneel in die Gereformeerde teologie as onderskeidelik 'sending' en 'evangelisasie' bekend gestaan het nie. Hiermee het hy die skyn van 'n teologiese fundering uitgeslaan onder 'n onderskeid wat dikwels verlammend gewerk het op die gesindheid van Gereformeerdes ten opsigte van evangelisering, omdat in die stryery oor wat nou eintlik sending en wat evangelisering is, en wie nou eintlik objekte van pastorale bearbeiding en wie van evangelisering is, die taak self dikwels links laat lê is.

\subsection{Dogmaties-teologiese fundering van die sending}

Soos te verwagte is, was daar in die Gereformeerde Kerke besondere belangstelling in die dogmatiese, en met name die trinitariese fundering van die sending. Hierdie belangstelling het as resultaat gehad belangrike bydraes soos die inougurele rede van H. du Plessis (1960c) oor Die Missiologie as teologiese wetenskap, waarin hy die moderne stand van besinning oor die Missiologie beskryf, en dan sy eie, Gereformeerde siening stel. Sy 
eie siening sluit in die trinitariese fundering van die sending, die Christologiese fundering en die eskatologiese fundering. Vervolgens benader hy die Missiologie vanuit die sendingobjek, om af te sluit met 'n bespreking van die ensiklopediese plek daarvan. Die teologiese fundering kom weer aan die orde in dieselfde skrywer se bydrae (ongedateerd) in Die saailand is die wêreld, naamlik "Die sendingroeping in verhouding tot die werk van God". In hierdie bydrae gaan hy in op die universaliteit van verlossing soos die Ou Testament dit openbaar (23-26), Christus as subjek van die sending, wat meebring dat sending 'n taak van die kerk self as liggaam van Christus is, en nie van genootskappe nie (26-29), en die kosmiese betekenis van Christus (29-35). P.J. Buys (1986b) het ook 'n belangrike bydrae gelewer met sy artikel oor "Die soewereiniteit van God en evangelisasie". Hierin bring hy die Gereformeerde leer oor verbond en uitverkiesing ter sprake, en ook van die volharding van die heiliges. Maar hy gaan verder en definieer soewereiniteit ook as die koningsheerskappy van Christus, wat soewerein sy kerk uitstuur na die wêreld om sy koningskap aan te kondig en daarom ook onvoorwaardelik gehoorsaam moet word. Vervolgens bespreek hy die implikasies van die soewereiniteit van God vir die inhoud van die evangelisasieboodskap en vir die metodes daarvan. D.C.S. van der Merwe, dogmatoloog en missioloog, het in sowel sy Th.M.-skripsie (1960 - "Sending en uitverkiesing") as Th.D.-proefskrif (1965 - Die Gereformeerde verbondsleer en sy betekenis vir die sending) op dogmatologiese terrein beweeg. In sy (ongedateerde) bydrae in Die saailand is die wêreld oor "Moderne sending en antieke denkwette" beweeg hy hom op die twee terreine van Dogmatiek en Filosofie.

\section{4 'Bekeringsteologie'}

F. Denkema (1988), missioloog van Potchefstroom, het hom met sy artikel oor "Bekering en sending" op hierdie terrein begewe, met 'n bespreking van die bekeringsmodelle by verskillende Christelike tradisies. Die onderwerp "Die plek van geloofsekerheid in die prediking, pastorale sorg, evangelisasie en sending in die lig van die verkiesing van God" (1982) is deur Van Rooy behandel. Onder andere word in die artikel die verwoestingswerk van die hiper-Calvinisme aangetoon, en word daarop gewys hoe 'n gesonde siening op die uitverkiesing tot sekerheid en blydskap lei. 


\subsection{Kerkregtelike/ekklesiologiese bydraes}

Wat onder hierdie onderwerp van belang is, is veral die bydrae van J.H.S. van der Walt (1986) oor "Die amp van die gelowige in reformatoriese perspektief en sy taak in evangelisasie".

\subsection{Algemeen}

Interessant onder hierdie afdeling is Sending, toekoms en strukture (1974) van D.C.S. van der Merwe. Tot watter mate elke teoloog ook maar kind van sy tyd is, blyk uit die onkritiese en selfs ietwat idealistiese houding teenoor apartheid (1974:33-41) wat in hierdie geskrif opval - iets wat die skrywer teenswoordig waarskynlik heelwat anders sou gestel het.

Oor die sendingkonferensie van die G.E.S. in 1976 het Botha (1977) 'n interessante artikel geskryf.

\section{Sendingpraktyk}

\subsection{Sendingstrategie en -beleid}

Verskeie onderwerpe kan hieronder gerangskik word, soos die artikel van S.J. van der Merwe (1988) oor "Finansiering van die sending" en dié van Buys (1988b) oor kerkgroei. Perspektiewe vir die toekoms word geopen in die artikel van Van Rooy (1990b) oor "Gereformeerde teologiese opleiding vir Afrika in die een-en-twintigste eeu". Die wenslikheid van tentmakerbediening en die opleiding van sodanige 'tentmakers', buitemuurse teologiese onderrig en fleksieonderrig, en van buigsaamheid van teologiese opleiding volgens die verskillende behoeftes van verskillende groepe, word aangetoon. Onder hierdie onderwerp hoort seker ook die publikasie van die Sinodale Sendingdeputate (1973) oor besluite van die verskillende nasionale sinodes insake sendingsake.

\subsection{Sendingmetodes en -middele}

Soos 'n mens kan verwag, het heelwat materiaal oor hierdie onderwerp verskyn, veral wat die prinsipiële besinning hieroor betref. I.J. van der Walt (1985) se lywige Die evangelie aan afgedwaaldes is een daarvan. Die sterk punte van hierdie geskrif lê in die massa interessante materiaal en inligting wat daarin saamgevat is, en ook in die duidelike standpunt daaroor dat evangelisering ' $n$ wesenlike taak van die kerk is. Die teologiese fundering van standpunte in die geskrif is soms ietwat skraal, en in sommige gevalle ooglopend vanweë 'n gebrek aan eksegetiese begronding. 
Daar is byvoorbeeld geen skriftuurlike fundering daarvoor dat die skrywer steeds vashou aan die tradisionele onderskeiding tussen sending en evangelisasie nie. Dit mag goed wees om Helberg (1986) se bydrae oor "'n Geprogrammeerde opleidingsprogram vir evangelisasie" saam met die boek van Van der Walt te bestudeer.

S.J. van der Merwe het meer as een grondige studie van evangeliseringsmedia gemaak. In sy Th.M.-skripsie (1987) wys hy dramatisering van Bybelse stof as sendingmetode af, maar dui terselfdertyd aan dat musiek en sang wel nuttig gebruik kan word. Sy Th.D.-proefskrif (1993) handel oor radio en televisie as missionêre media. Hierdie studie val op die terrein van die kommunikasiekunde eerder as op dié van teologie, maar dit is wel van belang dat hy oortuigend bewys dat televisie as medium, kragtens die eise wat daardie medium aan sy stof stel, totaal ongeskik is om die evangelie oor te dra. Sy bydrae oor radio-evangelisering is minder oortuigend, miskien veral omdat hy nie op die teologiese fundering van die Woord as God se medium van kommunikasie ingaan nie, en die geskrewe woord as "direkte kommunikasie" beskou terwyl hy die gesproke woord as "bemiddelde kommunikasie" tipeer (S.J. van der Merwe, 1993:187, 193).

A.E. Liphadzi (1988) is die eerste swart teoloog uit die Gereformeerde Kerke wat 'n bydrae lewer tot die missiologie, met sy artikel oor die evangelisering van die jeug. Sy kerklike agtergrond uit Venda, waar 'n besonder geseënde jeugbediening gevind word, was sekerlik vir hom nuttig ten opsigte van inspirasie en inligting.

Ten spyte van sendingmetodes en -middele is P.C. Kruger (1986) se bydrae oor Noodlynevangelisasie ook van belang.

\section{Kulturele, sosiale en politieke dimensies van sending}

\subsection{Kulturele dimensies}

I.J. van der Walt (1963) het in sy deeglike en omvangryke proefskrif 'n massa materiaal oor eiesoortige kerkvorming versamel. Sommige van die dinge wat hy aanbeveel, soos by voorbeeld danse en "ritmiese bewegings" $(1963: 263,264)$, is reeds met geesdrif ingevoer in swart Gereformeerde kerke, en dra by tot die vreugdevolle belewing van die erediens.

Die onderwerp van die huwelik in sendingperspektief het sy kwota aandag ontvang, soos blyk uit die D.D.-proefskrif van Geertsema (1960) oor die Christelik-etiese implikasies van die sewende gebod met betrekking tot die 
sending in Afrika, en die proefskrif van Venter (1975) oor poliginie as sendingprobleem - laasgenoemde veral interessant as 'n mens weet dat Venter nooit 'n sendeling was nie, maar voldoende belangstelling in die onderwerp getoon het om 'n proefskrif daaroor te skryf. In aansluiting hierby het Venter ook later (1977) 'n artikel in In die Skriflig publiseer oor die onderwerp "Het die kerk kultuurkerstening as sendingtaak?"

My eie belangstelling in hierdie onderwerp het gelei tot ' $n$ artikel (1973) in Missionalia oor "Witches and wizards in the light of Scripture". Van 'n ietwat ander opset is die artikel (1986) oor "The communities of Abazalwane at Kwa Sizabantu and elsewhere as a challenge to the world", waarin die resultate van 'n studieverblyf van drie maande tussen die ZoeloeChristene in Noord-Natal beskryf word, en waarin aangedui word hoe volkome daardie groepie Christene hulle tradisionele Zoeloegodsdiens vir 'n Bybels-Christelike geloof en lewenswyse verruil het.

Hoewel dit eintlik 'n eksegetiese studie is, lê die belang van J.C. Coetzee se Volk en Godsvolk in die Nuwe Testament (1965) vir die missiologie hoofsaaklik op kulturele terrein. In hierdie studie toon Coetzee aan dat in die openbaring die volkeregedagte nie losgelaat is nie, maar juis by sentrale momente na vore tree (Coetzee, 1965:317). Daar is volgens hom in die Nuwe Testament 'n organiese band tussen volk en Godsvolk: nie geskeie van mekaar nie (wêreldkerkgedagte), maar ook nie vereenselwig nie (volkskerkgedagte - Coetzee, 1965:319). Die voorwerp van sending is dus nie individue nie, maar volke, met die doel om elke volk in te bring in die Godsvolk onder die heerskappy van Jesus Christus (Coetzee, 1965:320). Verder is van belang Botha (1969:42-53) se artikel oor "Sending en die kultuursituasie van die Bantoe".

\subsection{Sosiale en politieke dimensies}

Wat die sosiale en politieke dimensie van die missiologiese besinning betref, is die brosjure van J.D. en S. du Toit, "Die Afrikaanse rassebeleid en die Skrif" (1981) van belang. Alhoewel die standpunte wat hierin verdedig word, nie op grondige eksegetiese studie berus nie, is die publikasie van belang omdat mense hulle nog steeds hierop beroep, sonder om van latere studies en eksegeties gegronde sinodebesluite kennis te neem. 'n Voorbeeld van J.D. du Toit se eksegetiese metode is sy gebruik van 'n teks soos Deuteronomium 22:11, waarin dit onder andere verbied word om 'n sterker dier langs 'n swakkere in te span, om 'n skriftuurlike fundering van 
apartheid te voorsien (Du Toit, 1981:16), of die argumentering vanuit die Babelgeskiedenis sonder enige verwysing na Pinkster (Du Toit, 1981:9).

Veel grondiger eksegetiese studie blyk uit die brosjure van $\mathrm{H}$. du Plessis (1963b), 'n Nuwe deurbraak. Hierin bespreek Du Plessis die eise wat die komende nuwe wêreldbeskawing, die Bantoe-Messianisme, en die ontmoeting van godsdienste aan die Christendom gaan stel. Verder word nuwe klanke - vir daardie tyd - gehoor in die vorm van 'n kritiese beoordeling van die praktyk van die beleid van eiesoortige ontwikkeling, en veral van kerklike apartheid (Du Plessis, 1963b:35). Ten slotte word gewys op die dringendheid van sendingwerk in Afrika (Du Plessis, 1963b:35-45). Meer tradisioneel in sy benadering is die brosjure van D.C.S. van der Merwe (1973), Kerk, volk en ras in die sendingbeleid van die Gereformeerde Kerk in Suid-Afrika, wat bedoel was om aan lede van jongeliedeverenigings leiding oor hierdie onderwerp te verskaf. Die skrywer handhaaf daar nog die siening dat "'n oorhoofse parlement oor alle volke en rasse in Suid-Afrika met een man, een stem, politieke en staatkundige selfmoord nie net vir die blankedom beteken nie, maar ook vir die ander" (Van der Merwe, 1973: 27), en in aansluiting daarby vind hy dit "vrugbaar en stigtelik om Kleurlinge en Afrikaners in twee onderskeie nasionale sinodes te groepeer" (Van der Merwe, 1973:28, 29).

'n Toon van geloofsoptimisme kenmerk die brosjure van D.C.S. van der Merwe (1983), Afrika is nie donker nie, wat op die terrein van die Bybelse fundering beweeg, maar waarvan die speerpunt miskien tog in die bespreking van kultureel-politieke omstandighede in Afrika te vinde is.

Verder is daar die artikels van D.C. Coetsee (1986) oor "The world of God - a challenge to the church", en die uitgebreide artikel van H. du Plessis (1968) in die eerste publikasie van die Suid-Afrikaanse Werkgemeenskap vir Sendingwetenskap, oor "Die kerstening van die Bantoe in 'n tyd van sekularisasie en sekularisme". $\mathrm{Na}$ 'n uitgebreide beskrywing van die verskynsel van sekularisasie, verskaf Du Plessis die antwoord van die Skrif op hierdie uitdaging: verkondig die koninkryk wat gekom het, ondermyn sekularisasie deur 'n voorbeeld van 'n lewe wat met God rekening hou. Verder bespreek hy onder andere die Koning van die koninkryk en sy geregtigheid. M.A. Kruger se proefskrif (1973) handel ook oor hierdie studieveld, naamlik, Vryheid vir die ganse mensheid? Die vryheidsgedagte in die ekumeniese diskussies. Hierin toon hy aan dat in die ekumeniese diskussies vryheid gesien word as die resultaat van die druk van humanistiese filosofie, in plaas van die verkondiging van die evangelie. 
I.J. van der Walt (1972) het daarna ook 'n goedbestudeerde studie gelewer oor "Gemeenteopbou in die nuwe Afrika". Hy sien die 'nuwe' van die nuwe Afrika veral in die bevolkingsontploffing en die opkoms van nasionalisme en sekularisme. Gemeenteopbou omskryf hy as 'die kwantitatiewe daarstelling' van die kerk, asook die kwalitatiewe verdieping daarvan, wat sig onder andere openbaar in die ontplooiing van die amp, eiesoortige kerkvorming, 'n eie teologiese ontplooiing en kerklike eenheid.

Ten slotte is hier ook van belang die artikel van Duvenage (1986) oor "Evangelisasie by verslaafdes".

\section{Die kommunikasie van die evangelie}

M. Venter (1967) het die studies oor hierdie onderwerp ingelei met sy Th.M.-skripsie oor die onderwerp Sendingprediking. Hy benader die onderwerp eksegeties, deur in navolging van W.J. Snyman onderskeid te maak tussen "stigtingsprediking" en "stigtelike prediking" (Venter, 1967: 2,3 ), en missiologies, deur aan te dui hoedat verskillende gehore op verskillende maniere benader moet word (Venter, 1967:12). Die bekende Potchefstroomse akademikus, prof. J.H. Coetzee, het voor een van die eerste kongresse van die Suid-Afrikaanse Werkgemeenskap vir Sendingwetenskap opgetree met ' $n$ lesing oor "Kommunikasie en die tradisionele religie van die Bantoe" (1969).

My eie belangstelling in die onderwerp het neerslag gevind in die artikel "Kommunikasie en taal" in Lux Mundi (1969) en my proefskrif (1970) oor Language and culture in the communication of the Christian message as illustrated by the Venda Bible. Die hoofaksent in hierdie proefskrif val op die Vendaterme wat in die vertaling van P.E. Schwellnus gebruik is om Bybelse begrippe soos heiligheid, geregtigheid, geloof, seën en God te vertaal, en die verwringing van die boodskap wat deur die gebruik van ontoereikende terme kan geskied. Later is dieper op die onderwerp van kommunikasie en kultuur ingegaan in die artikel oor "Die kommunikasie van die evangelie aan die Bantoe in Suidelike Afrika gesien teen sy geestelik-kulturele agtergrond" (Van Rooy, 1976:89-132).

Die hele vraagstuk van transkulturele kommunikasie van die evangelie, toegepas in die konteks van Afrika, is uitgewerk in 'n artikel (Van Rooy, 1988:144-160), waarin, benewens 'n uiteensetting van die beginsels van transkulturele kommunikasie, aangedui word hoe die Pauliniese kerugma 
baie pertinent en sinvol antwoord op die dwalings van die tradisionele gelowe van Afrika.

\section{Godsdienste}

Die enigste teologiese bydrae vanuit die GKSA oor die godsdienswetenskap in die algemeen is die artikel in Missionalia, onder die titel, "Christ and the religions: The issues at stake" (Van Rooy, 1985:3-13). In hierdie artikel word die benadering tot die godsdienste deur verskillende teologiese strominge uiteengesit. Die etnologies-godsdienswetenskaplike werk van I.J. van der Walt (1982), Defining Ethnologv and Religious Science, lewer egter ook 'n belangrike besinning vir die Missiologie, veral in die bespreking van aspekte van die religie van Afrika.

Van belang in die konteks van Suidelike Afrika is die artikel van Buys (1988a), "Evangelisering in 'n godsdienstig plurale gemeenskap". Daarin bespreek hy die uitdaging van evangelisering in die raamwerk van nominalisme, sekularisme, die Pinksterbeweging en die onafhanklike kerke, en die verskillende godsdienste. Hy dui vervolgens aan hoe dialoog as getuienis gebruik kan word en wat die waarde van Bybelskoolbediening vir die evangelisering van die onafhanklike kerke is.

In The Word of God for Africa (Van Rooy, 1990a) is gepoog om die antwoord van die Skrif op elke spesifieke aspek van die geloof van die swart man aan te dui. Aspekte wat betrek is, sluit die volgende in: die idee van die beperkte kosmiese goed, magie en waarsêery, voorvaderverering, besetenheidskultusse en intermenslike verhoudings. Alleen die Godsbegrip word nie hierin behandel nie. Die Godsbegrip kom wel aan die orde in die proefskrif oor Yahweh and Modimo. The relationship between God and man in the Old Testament seen in the context of African concepts of God (Van Rooy, 1994b). In dié proefskrif word eerstens aangetoon dat daar, in teenstelling met wat tot dusver algemeen in geskrifte oor die Godsbegrip van Afrika beweer word, nie slegs een nie, maar minstens ses verskillende modelle van Godsbegrippe in Afrika voorkom. Verder word aangedui hoedat, in teenstelling met die populêre idee van vele Afrika-teoloë, daar 'n grondliggende verskil bestaan tussen die Godsbegrip van die $\mathrm{Ou}$ Testament en elkeen van hierdie ses Godsbegrippe. Die verskille is te vinde op die terrein van God se soewereiniteit as Skepper, sy persoonlike aard as God, sy intieme en direkte betrokkenheid by die skepping en die geskiedenis, sy oordeel en verlossing, verkiesing en genadeverbond, sy intieme, persoonlike gemeenskap met sy uitverkorenes, en die duidelike 
openbaring van sy wil. Die verskille tree veral duidelik na vore op die terrein van die etiek en eskatologie (persoonlik sowel as kosmies). Verder kan in verband met hierdie onderwerp genoem word Botha (s.j.) se bydrae oor "Heidense reste in die jong kerke".

Oor die Godsbegrip van die Islam is redelik breedvoerig ingegaan in 'n artikel met die titel, "Is Allah die Here"? (Van Rooy, 1994a:103-112) Hierin word gekonkludeer dat die Islam wel, soos die Judaïsme, 'n skeefgetrokke Godsbegrip het, maar dat 'n mens nie mag sê dat Allah, objektief gesproke, ' $n$ afgod is nie, aangesien wat Mohammad oor Allah sê, hy by Christene en Jode gehoor het. Die Islam sluit dus ondanks die vervalsings wat Mohammad daarin aangebring het, aan by God se besondere openbaring in die Heilige Skrif.

Interessant is ten slotte Buys (1988a:121-130) se bydrae oor "Evangelisering in 'n godsdienstig plurale gemeenskap".

\section{Sinkretisme}

Verskeie persone het hulle met hierdie aspek van die missiologiese besinning besig gehou. M.A. Kruger het drie publikasies (1971, 1972, 1983) aan die Z.C.C. gewy, terwyl Van Rooy (1964) se Th.M.-skripsie (1964) handel oor sinkretisme in Vendaland. Op grond van die resultate van Van Rooy (1964) se navorsing het daar ook verskeie publikasies in Venda, Sotho, Zoeloe en Shona oor die onderwerp verskyn. Oor sinkretisme binne die geledere van die Gereformeerde Kerke is baie insiggewend die studie van A.G. Schutte oor "Swart Doppers" (1974), waarin hy aantoon hoedat 'n beduidende persentasie swart Gereformeerdes nog deelneem aan voorvaderverering en aan swart magie glo. Verder kan in verband met hierdie onderwerp genoem word Botha (s.j.) oor "Heidense reste in die jong kerke".

\section{Sendinggeskiedenis}

Op hierdie gebied het heelwat van belang verskyn. Die heel eerste is die proefskrif van P.J.S. de Klerk (1923), waarin die sendingbeleid van die verskillende sendinginstansies in Suid-Afrika sedert die vroegste begin tot ongeveer 1920 beskryf en beoordeel word. De Klerk onderskei tussen "genootskaplike sending" (soos byvoorbeeld dié van die Londense Sendinggenootskap), "kerkgenootskaplike sending" (soos byvoorbeeld dié van die Nederduitse Gereformeerde Kerk), en "kerklike sending", dit wil sê dié van die Gereformeerde Kerk in Suid-Afrika, wat tot op daardie stadium baie 
beperk in omvang was, maar nogtans volgens De Klerk se beoordeling volgens suiwer skriftuurlike beginsels gedryf is.

Spoelstra (s.j.:151-192) het in sy artikel "Kolonialisme en ons sendingkrisis gedurende die vorige eeu" die oorsake aangedui van veel weerstand teen sending in die geledere van die Gereformeerde Kerke.

H. du Plessis (1960b) lewer 'n belangrike bydrae in sy brosjure Het die Christendom gefaal? waarin hy nagaan in watter mate die Christendom in verskillende wêrelddele teenslae ondervind en hy die oorsake daarvan en antwoord daarop aandui.

'n Belangrike prinsipiële bydrae is dié van Spoelstra (1972:45-53) oor die onderwerp, "Kan Sendinggeskiedenis en Kerkgeskiedenis ensiklopedies geskei word?" Spoelstra kom tot die bevinding dat die vak Sendinggeskiedenis volgens dieselfde historiese beginsels as Kerkgeskiedenis beofen moet word, en dus ' $n$ subdissipline van die Kerkgeskiedenis is (Spoelstra, 1972:51). Nog 'n argument wat hy noem, is dat kerk en sending andersins geskei word. Die vraag wat hy nie in die artikel beantwoord nie, is natuurlik hoe die missionêre dimensie dan in die Sendinggeskiedenis tot sy reg kom? Is dit dan nog werklik Sendinggeskiedenis? 'n Mens kry die indruk dat Spoelstra met Sendinggeskiedenis iets anders bedoel as wat missioloë daarmee bedoel (1972:50).

Vir omvattende inligting oor die sendingwerk van die Gereformeerde Kerke gedurende die eerste helfte van die twintigste eeu, is die brosjure (1953) wat deur die Sinodale Sendingdeputate uitgegee is, essensieel, aangesien daar baie inligting verskaf word wat elders moeilik bekombaar is.

Op biografiese terrein is die volgende bydraes oor $\mathrm{H}$. du Plessis van historiese waarde, aangesien dit deur persone geskryf is wat die gebeure wat daarin beskryf is, meegemaak het en Du Plessis persoonlik geken het (al vier bydraes kom voor in Gaan dan heen ... (Du Plessis, 1976)): Jooste oor Du Plessis se werk as sendeling in Noord-Transvaal (1976:13-34); Schutte oor sy werk as sendeling op die Witwatersrand (1976:35-39); Botha oor sy werk in die opleiding van nie-blanke predikante (1976:4045); S.P. van der Walt (1976:46-49) oor sy werk aan die Teologiese Skool te Potchefstroom.

H.A. Louw het belangrike artikels gelewer oor pres. Paul Kruger (1987: 35-41) en oor prof. Jan Lion-Cachet as sendingmanne (1989:40-47). 
In 1975 het 'n aantal teoloë van die Teologiese Skool op Potchefstroom 'n publikasie die lig laat sien oor Revival of Reformasie? waarin die verskynsel van godsdienstige herlewing baie eensydig van die hand gewys is, asof dit pure Metodisme sou wees. 'n Gesonde korrektief hierop is die artikel van D.C.S. van der Merwe (1975:25-36): "Metodiste, Metodisme en sending". Dit het destyds moed gekos om teen die stroom van veroordeling in te gaan, en Van der Merwe se bydrae moet ook om daardie rede waardeer word.

Twee brosjures oor die onderwerp van herlewing, 'n verskynsel wat ook sendinghistories van belang is, het ook die lig gesien: Kwa Sizabantu. Dieptestudie van 'n herlewing (Van Rooy, 1987b), waarin die verloop, aard en invloed van die herlewing te Kwa Sizabantu beskryf word en $\mathrm{Her}$ lewing en reformasie (Van Rooy, 1989), waarin aangetoon word dat die verskynsel van herlewing nie iets 'ongereformeerds' is nie, maar Bybels gefundeer kan word en onmisbaar is vir die welsyn en uitbreiding van die kerk.

Op die oomblik werk B. Spoelstra aan 'n geskiedenis van die Gereformeerde Kerke se sendingwerk in Venda, gedeeltelik gebaseer op materiaal wat deur H.A. Louw versamel is. Die redelik uitgebreide geskrif sal hopelik in die loop van 1994 gepubliseer word. Dit sou onbillik wees om 'n mens op hierdie stadium aan 'n beoordeling te waag, aangesien die boek nog onafgerond is. Dit lyk egter of dit veel belangrike inligting oor hierdie onderwerp sal kan verskaf.

\section{Samevattend oor die relevansie van hierdie bydraes}

Die meeste van die bydraes wat in hierdie artikel vermeld word, is minstens in 'n mate relevant, in die sin dat hulle 'n nuttige oorsig oor die betrokke onderwerp bied. In sommige gevalle, soos by voorbeeld die proefskrif van 1.J. van der Walt (1963), is dit selfs 'n baie volledige oorsig. Sommige van die bydraes het egter ook nuwe perspektiewe na vore gebring. Hiervan is die belangrikste die volgende:

Aangesien ' $n$ hele aantal van die bydraes hier genoem van die hand van die skrywer van die artikel self is, is dr. P. J. Buys gevra om 'n evaluering daarvan te skryf, wat in hierdie voetnoot ingesluit word. Die evaluering van Buys is deur die missioloog M.A. Kruger gekontroleer. 
Perspektiewe op die terrein van die skriftuurlike fundering van sending:

'n Banier van die volke (1963a) van Hugo du Plessis, die proefskrif (1989) van Buys oor Die verhouding tussen gemeenteopbou en evangelisering, en die artikels van M.A. Kruger (1985 en 1988) oor die definiëring van sending en evangelisering.

Oor die politieke dimensies van sending was 'n Nuwe deurbraak van Hugo du Plessis (1963b) 'n moedige getuienis wat van 'n versiende blik blyke gee.

Oor die Sendinggeskiedenis gee die artikel van Spoelstra (1972:45-53) blyke van ' $n$ verkennende gees.

As 'n mens enkele oorwegende tendense in hierdie oorsig moes aandui, kan 'n mens die kenmerkende belangstelling in prinsipiële begronding noem, wat blyk uit die meeste bydraes van H. du Plessis, D.C.S. van der Merwe, en sommige van die publikasies van P.J. Buys (1989), Van Rooy (1966) en B. Spoelstra. Van Rooy het heelwat oorspronklike navorsing

- "Die kommunikasie van die evangelie aan die Bantoe in Suidelike Afrika" (Van Rooy, 1976:89-132): Vir nuwe sendelinge wat onder swart mense moet gaan werk, is hierdie 'n waardevolle artikel omdat dit getuig van weloorwoë kennis van die onderwerp en dit ook uitkom by heel praktiese riglyne.

- "The Communities of Abazalwane at Kwa Sizabantu" (Van Rooy, 1986:76-84): Dit is 'n goeie wetenskaplike artikel wat ook spreek van deurleefde spiritualiteit.

- "Die tradisionele Afrika-wêreldbeskouing en wat die Bybel daaroor sê" (Van Rooy, 1987a:): 'n Onmisbare oriëntering vir oningewydes wat betrokke wil raak by sending onder mense wat nog tot 'n meerdere of mindere mate in tipiese Afrika-denke vasgevang is.

- "Transkulturele kommunikasie van die evangelie" (Van Rooy, 1988:144-160): Verskillende benaderings tot effektiewe kommunikasie wat enersyds aansluitend is sonder om sinkretisties te wees en andersyds ook konfronterend waar dit nodig is.

- "Gereformeerde teologiese opleiding vir Afrika in die een-en-twintigste eeu" (Van Rooy, 1990b:283-294): In hierdie artikel blyk Van Rocy se fyn aanvoeling vir die werklike nood van die Christelike Kerk in Afrika.

- Yahweh and Modimo (Van Rooy, 1994b): In hierdie (tweede) proefskrif word 'n leeftyd se wetenskaplike ondersoek en praktiese sendingervaring saamgetrek. Dit is waardevol nie net vanweë die deeglike uiteensetting van die Godsbegrippe in Afrika en die implikasies daarvan vir mense se lewens nie, maar ook vir die deeglike vergelyking daarmee met die Ou-Testamentiese Godsopenbaring. 
gedoen op die terrein van die kommunikasie van die evangelie in die Afrikakonteks (1964, 1969, 1970, 1976, 1986, 1987a, 1988, 1990a, 1994b), en oor die onderwerp van herlewing (1986, 1987b, 1989).

\section{Bibliografie}

BOTHA, L.J. s.j. 'n Beskouing oor: Heidense reste in die jong kerke. (In Floor, L., red. Die saailand is die wêreld. Hammanskraal: Teologiese Skool. p. 37-61.)

BOTHA, L.J. 1969. Die sending en die kultuursituasie van die Bantoe. In die Skriflig, 3 (9):42-53, Febr. - Maart.

BOTHA, L.J. 1976. Prof. Hugo du Plessis en die opleiding van nie-blanke predikante. (In Du Plessis, H. Gaan dan heen ... Pro Rege : Potchefstroom. p. $40-45$.)

BOTHA, L.J. 1977. Die sendingkonferensie van die G.E.S. te Kaapstad van 26 Augustus 1976 - 'n terugblik. In die Skriflig, 11 (41):4-13, Maart.

BUYS, P.J. 1986a. Bybelse gesigspunte oor die evangeliseringstaak van die kerk. (In Van der Walt, B.J., red. Sodat my huis vol kan word. Potchefstroom: IRS. p. 1-12.)

BUYS, P.J. 1986b. Die soewereiniteit van God en evangelisasie. (In Van der Walt, B.J., red. Sodat my huis vol kan word. Potchefstroom: IRS. p. 1327.)

BUYS, P.J. 1986c. Die verhouding tussen evangelisasie en gemeenteopbou. (In Van der Walt, B.J., red. Sodat my huis vol kan word. Potchefstroom: IRS. p. 54-63.)

BUYS, P.J. 1988a. Evangelisering in 'n godsdienstig plurale gemeenskap. (In Denkema, F. e.a., reds. Evangeliseer! Pretoria: N.G. Kerkboekhandel. p. 121-130.)

BUYS, P.J. 1988b. Kerkgroei: 'n Kritiese evaluering van die kernaspekte van die Church Growth Movement. In die Skriflig, 22 (87):2-16, September.

BUYS, P.J. 1989. Die verhouding tussen gemeenteopbou en evangelisering. 'n Eksegetiese ondersoek na die betekenis van tersaaklike woorde in die Nuwe Testament en die implikasies daarvan vir die verhouding tussen die bewaring en vermeerdering van die kerk. Potchefstroom: PU vir CHO. (Th.D.-proefskrif.) $283 \mathrm{p}$.

COETSEE, D.C. 1986. The World of God - a Challenge to the Church. Missionalia, 14 (3):119-126, November.

COETZEE, J.C. 1965. Volk en Godsvolk in die Nuwe Testament. 'n Eksegetiese studie. Potchefstroom: PU vir CHO. (Th.D.-proefskrif.) 329 p.

COETZEE, J.H. 1969. Kommunikasie en die tradisionele religie van die Bantoe. (In Bosch, D.J., red. Sodat hulle kan verstaan. Kommunikasie as sendingprobleem in Afrika. Pretoria : N.G. Kerk-Boekhandel. p. 11-37.) 
DE KLERK, P.J.S. 1923. Kerk en sending in Suid-Afrika. Amsterdam : H.A. van Bottenburg. Amsterdam: Vrije Universiteit. (D.D.-proefskrif.) 190 p.

DENKEMA, F. 1988. Bekering en sending: 'n Vergelyking van enkele sendingmodelle. (In Denkema, F. e.a., reds. Evangeliseer! Pretoria: N.G. Kerkboekhandel. p. 131-143.)

DU PLESSIS, H. 1960a. Geskjedenis van die Sendingwetenskap. Potchefstroom : Pro Rege. 186 p.

DU PLESSIS, H. 1960b. Het die Christendom gefaal? Potchefstroom : Van der Spoel. $16 \mathrm{p}$.

DU PLESSIS, H. 1960c. Die Missiologie as teologiese wetenskap. Potchefstroom : PU. 39 p. (Inougurele rede - PU vir CHO.)

DU PLESSIS, H. 1963a. 'n Banier van die volke. Die Woord van God in en vir die wêreld. Potchefstroom : Pro Rege. 205 p.

DU PLESSIS, H. 1963b. 'n Nuwe deurbraak. Potchefstroom: Pro Rege. 45 p.

DU PLESSIS, H. 1968. Die kerstening van die Bantoe in 'n tyd van sekularisasie en sekularisme. (In Bosch, D.J., red. Sendingwetenskap vandag. 'n Terreinverkenning. Pretoria : N.G. Kerkboekhandel. p. 63-90.)

DU PLESSIS, H. s.j. Die sendingroeping in verhouding tot die werk van God. (In Floor, L., red. Die saailand is die wêreld. Hammanskraal: Teologiese Skool. p. 23-36.)

DU PLESSIS, H. 1976. Gaan dan heen ... 'n Keur uit die geskrifte van wyle prof. H. du Plessis. Uitgegee onder redaksie van Van der Merwe, D.C.S. en Van der Walt, I.J. Potchefstroom : Pro Rege. 328 p.

DU PLESSIS, J. van V. 1982. Sending en evangelisasie - 'n ander weg ? In die Skriflig, 16 (61):43-45, Maart.

DU TOIT, J.D. \& DU TOIT, S. 1981. Die Afrikaanse rassebeleid en die Skrif. Noordbrug : D. du Toit. 34 p.

DUVENAGE, A.P.C. 1986. Evangelisasie by verslaafdes. (In Van der Walt, B.J., red. Sodat my huis vol kan word. Potchefstroom : IRS. p. 122-131.)

FLOOR, L. 1964. In dieselfde spore. 'n Ondersoek na die struktuur van die sendingwerk. Potchefstroom : Die Evangelis. 96 p.

FLOOR, L., red. s.j. Die saailand is die wêreld. Hammanskraal : Teologiese Skool van die Gereformeerde Kerk in Suid-Afrika. 192 p.

FLOOR, L. s.j. Die Exodus-motief in die Swart Teologie. (In Floor, L., red. Die saailand is die wêreld. Hammanskraal : Teologiese Skool van die Gereformeerde Kerk. p. 119-150.)

FLOOR, L. 1988. Die missionêre gemeente. (In Denkema, F. e.a., reds. Evangeliseer! Huldigingsbundel L.J. Botha. Pretoria: N.G. Kerkboekhandel. p. 94-100.)

GEERTSEMA, P.G. 1960. Die Christelik-etiese implikasies van die sewende gebod met betrekking tot die sending in Suid-Afrika. Pretoria : UP. (D.D.-Proefskrif.) $152 \mathrm{p}$. 
HELBERG, A.N. 1986. 'n Geprogrammeerde opleidingsprogram vir evangelisasie. (In Van der Walt, B.J., red. Sodat my huis vol kan word. Potchefstroom : IRS p. 46-53.)

JOOSTE, J.P. 1976. Prof. Hugo du Plessis se werk as sendeling in NoordTransvaal 1928-1950. (In Du Plessis, H. Gaan dan heen ... Potchefstroom : Pro Rege. p. 13-34.)

KRUGER, M.A. 1970. In hoever behoort sending tot die wese van die kerk? In die Skriflig, 4 (16):28-38, Desember.

KRUGER, M.A. 1971. Die Zion Christian Church - 'n religieuse beweging in 'n tyd van ontwrigting? Potchefstroom : PU vir CHO. (Th.M.-verhandeling.) 199 p.

KRUGER, M.A. 1972. Die oorsake vir die ontstaan en besondere aard van die Zion Christian Church. In die Skriflig, 6 (21):13-32, Maart.

KRUGER, M.A. 1973. Vryheid vir die ganse mensheid? Die vryheidsgedagte in die ekumeniese diskussies. Potchefstroom : PU vir CHO. (Th.D.-proefskrif.) $487 \mathrm{p}$.

KRUGER, M.A. 1983. The Zion Christian Church in the Light of the Understanding of Scripture by the Reformation. In die Skriflig, 17 (66):2-12, Julie.

KRUGER, M.A. 1985. Evangelizesthai (om te evangeliseer) en verwante woorde in die NT. In die Skriflig, 19 (73):29-41, Maart.

KRUGER, M.A. 1988. Waarom "evangeliseer" ? (In Denkema, F. e.a., reds. Evangeliseer! Pretoria : N.G. Kerkboekhandel. p. 189-199.)

KRUGER, P.C. 1986. Noodlynevangelisasie. (In Van der Walt, B.J., red. Sodat my huis vol kan word. Potchefstroom: IRS p. 161-170.)

LIPHADZI, A.E. 1988. Evangelising the Youth. (In Denkema, F. e.a., reds. Evangeliseer! Huldigingsbundel L.J. Botha. Pretoria : N.G. Kerkboekhandel. p. 115-120.)

LOUW, H.A. 1987. President S.J.P. Kruger en die sending. In die Skriflig, 21 (83):35-41, September.

LOUW, H.A. 1989. Ds. Jan Lion Cachet as sendingman. In die Skriflig, 23 (92):40-47, Desember.

SCHUTTE, A.G. 1974. Swart Doppers? Stad, stamtradisie en Bantoekerk. Pretoria : N.G. Kerkboekhandel. 200 p.

SCHUTTE, J.A. 1976. Prof. Hugo du Plessis as sendeling op die Witwatersrand. (In Du Plessis, H. Gaan dan heen ... Potchefstroom: Pro Rege. p. 35-39.)

SINODALE DEPUTAATSKAP VIR SENDING. 1953. Die sending van die Gereformeerde Kerk in Suid-Afrika. Pretoria : V \& R Drukkery. 63 p.

SINODALE SENDINGDEPUTATE. 1973. Besluite van die nasionale sinode van die Gereformeerde Kerk in S.A. insake sending- en aanverwante sake. Potchefstroom : Pro Rege. $78 \mathrm{p}$. 
SNYMAN, P.C. 1972. 'n Ontleding van die prediking in die Nuwe Testament met die oog op die opbou van die kerk. (In Bosch, D.J. Gemeenteopbou in Afrika. Pretoria : N.G. Kerk-Boekhandel. p. 100-123.)

SPOELSTRA, B. s.j. Kolonialisme en ons sendingkrisis gedurende die vorige eeu. (In Floor, L., red. Die saailand is die wêreld. Hammanskraal : Teologiese Skool van die Gereformeerde Kerk. p. 151-192.)

SPOELSTRA, B. 1972. Kan Sendinggeskiedenis en Kerkgeskiedenis ensiklopedies geskei word? In die Skriflig, 6 (23):45-53, September.

SPOELSTRA, B. \& LOUW, H.A. 1994. Die geskiedenis van die sendingwerk van die Gereformeerde Kerke in Vendaland. Ongepubliseerde manuskrip. $161 \mathrm{p}$.

VAN DER MERWE, D.C.S. 1960. Sending en uitverkiesing. Potchefstroom : PU vir CHO. (Th.M.-verhandeling.) $100+$ xxxiii p.

VAN DER MERWE, D.C.S. 1965. Die Gereformeerde verbondsleer en sy betekenis vir die sending. Potchefstroom : PU vir CHO. (Th.D.-proefskrif.) $354 \mathrm{p}$.

VAN DER MERWE, D.C.S. s.j. Moderne sending en antieke denkwette. (In Floor, L., red. Die saailand is die wêreId. Hammanskraal : Teologiese Skool van die Gereformeerde Kerk. p. 75-102.)

VAN DER MERWE, D.C.S. 1973: Kerk, volk en ras in die sendingbeleid van die Gereformeerde Kerk in Suid-Afrika. Potchefstroom : Die skrywer. $65 \mathrm{p}$.

VAN DER MERWE, D.C.S. 1974. Sending, toekoms en strukture. Potchefstroom : Die skrywer. $66 \mathrm{p}$.

VAN DER MERWE, D.C.S. 1975. Metodiste, Metodisme en sending. In die Skriflig, 9 (36):25-36, Desember.

VAN DER MERWE, D.C.S. 1983. Afrika is nie donker nie. Die Bybel en/in Afrika. Potchefstroom : Khomas. $50 \mathrm{p}$.

VAN DER MERWE, S.J. 1987. Missiologiese beoordeling van dramatisering van Bybelse stof as sendingmetode. Potchefstroom : PU vir CHO. (Th.M.verhandeling.) $150 \mathrm{p}$.

VAN DER MERWE, S.J. 1988. Finansiering vir die sending. (In Denkema e.a., reds. Evangeliseer! Pretoria : N.G. Kerkboekhandel. p. 161-175.)

VAN DER MERWE, S.J. 1993. 'n Prinsipiële beoordeling van radio en televisie as missionêre media in Suid-Afrika. Potchefstroom: PU vir CHO. (Th.D.-proefskrif.) $362 \mathrm{p}$.

VAN DER WALT, I.J. 1963. Eiesoortigheid en die sending. Eiesoortige kerkvorming as missiologiese probleem met besondere verwysing na SuidAfrika. Potchefstroom : Pro Rege. 502 p.

VAN DER WALT, I.J. 1972. Gemeenteopbou in die nuwe Afrika. (In Bosch, D. J., red. Gemeenteopbou in Afrika. Pretoria : N.G. Kerkboekhandel. p. 29-55.) 
VAN DER WALT, I.J. 1982. Defining Ethnology and Religious Science. Potchefstroom : Universum. $176 \mathrm{p}$.

VAN DER WALT, I.J. 1985. Die evangelie aan afgedwaaldes. Handleiding vir evangelisasie. Potchefstroom : Universum. 399 p.

VAN DER WALT, J.H.S. 1986. Die amp van die gelowige in reformatoriese perspektief en sy taak in evangelisasie. (In Van der Walt, B.J., red. Sodat my huis vol kan word. Potchefstroom : IRS. p. 28-45.)

VAN DER WALT, S.P. 1976. Prof. Hugo du Plessis in Potchefstroom. (In Du Plessis, H. Gaan dan heen ... Potchefstroom : Pro Rege. p. 46-49.)

VAN ROOY, J.A. 1964. Sinkretisme onder die separatistiese sektes in Vendaland. Potchefstroom : PU vir CHO. (Th.M.-verhandeling.) $62 \mathrm{p}$.

VAN ROOY, J.A. 1966. Kerk en sending. Potchefstroom : Die Evangelis. $56 \mathrm{p}$.

VAN ROOY, J.A. 1969. Kommunikasie en taal. (In Bosch, D. J., red. Sodat hulle kan verstaan. Pretoria : N.G. Kerkboekhandel. p. 108-129.)

VAN ROOY, J.A. 1970. Language and Culture in the Communication of the Christian Message as Illustrated by the Venda Bible. Potchefstroom : PU vir CHO. (Th.D.-proefskrif.) $214 \mathrm{p}$.

VAN ROOY, J.A. 1973. Witches and Wizards in the Light of Scripture. Missionalia, I (3):136-137, November.

VAN ROOY, J.A. 1976. Die kommunikasie van die evangelie aan die Bantoe in Suidelike Afrika gesien teen sy geestelik-kulturele agtergrond. (In Van der Walt, B.J., red. Kontak en kommunikasie. Potchefstroom : IRS. p. 89-132.)

VAN ROOY, J.A. 1982. Die plek van geloofsekerheid in die prediking, pastorale sorg, evangelisasie en sending in die lig van die verkiesing van God. In die Skriflig, 16 (61):2-19, Maart.

VAN ROOY, J.A. 1985. Christ and the Religions: The Issues at Stake. Missionalia, 13 (1):3-13, April.

VAN ROOY, J.A. 1986. The Communities of Abazalwane at Kwa Sizabantu and Elsewhere as a Challenge to the World. Missionalia, 14 (2):76-84, August.

VAN ROOY, J.A. 1987(a). Die tradisionele Afrika-wêreldbeskouing en wat die Bybel daaroor sê. (In Van der Walt, B.J., red. Julle sal my getuies wees. Potchefstroom : IRS. p. 45-48.)

VAN ROOY, J.A. 1987(b). Kwa Sizabantu. Dieptestudie van 'n herlewing. Vereeniging : Reformatoriese Uitgewers. $41 \mathrm{p}$.

VAN ROOY, J.A. 1988. Transkulturele kommunikasie van die evangelie. (In Denkema, F. ea., reds. Evangeliseer! Pretoria : N.G. Kerkboekhandel. p. 144-160.)

VAN ROOY, J.A. 1989. Herlewing en reformasie. Potchefstroom : IRS. 29 p. VAN ROOY, J.A. 1990(a). The Word of God for Africa. Potchefstroom : IRS. $37 \mathrm{p}$. 
VAN ROOY, J.A. 1990(b). Gereformeerde teologiese opleiding vir Afrika in die een-en-twintigste eeu. In die Skriflig, 24 (3):283-294, September.

VAN ROOY, J.A. 1994(a). Is Allah die Here ? In die Skriflig, 28 (1):103-112, Maart.

VAN ROOY, J.A. 1994(b). Yahweh and Modimo. The Relationship between God and Man in the Old Testament Seen in the Context of African Concepts of God. Potchefstroom : PU vir CHO. (Th.D.-proefskrif.) 201 p.

VENTER, M. 1967. Sendingprediking. Potchefstroom : PU vir CHO. (Th.M.-verhandeling.) $64 \mathrm{p}$.

VENTER, M. 1975. Poliginie as sendingprobleem. Potchefstroom : PU vir CHO. (Th.D.-proefskrif.) 389 p.

VENTER, M. 1977. Het die kerk kultuurkerstening as sendingtaak? In die Skriflig, 11 (41):30-37, Maart. 